\title{
Sharks that eat sharks: opportunistic predation by wobbegongs
}
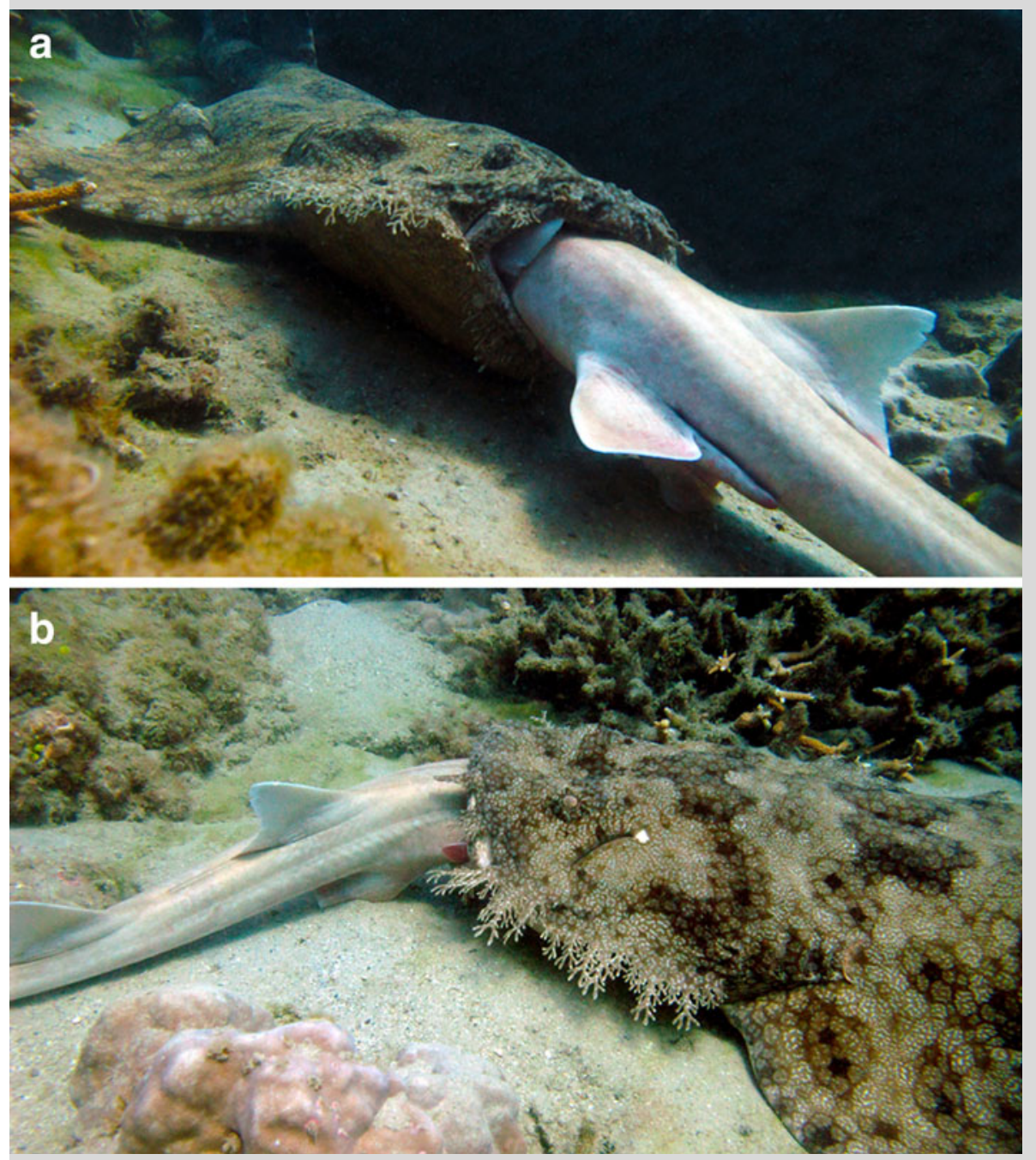

Fig. 1 a, b Predation of Chiloscyllium punctatum by Eucrossorhinus dasypogon in the Keppel Islands, Great Barrier Reef, Australia (Photo: Tom Mannering)
Wobbegong sharks (family Orectolobidae) are demersal ambush predators of benthic invertebrates, cephalopods, teleost fishes, and, in larger species, occasionally other sharks (Compagno 2001; Huveneers et al. 2007). Field observations of predation events are rare on coral reefs, and trophic status is usually assigned using stomach content data from collected specimens (Huveneers et al. 2007).

At midday on 1 August 2011, while conducting an underwater visual census of fishes on the fringing reef of Great Keppel Island (Great Barrier Reef, Australia), the authors encountered a tasselled wobbegong shark (Eucrossorhinus dasypogon, $\sim 125 \mathrm{~cm}$ TL) lying on the substratum with the head of a brown-banded bamboo shark (Chiloscyllium punctatum, $\sim 100 \mathrm{~cm} \mathrm{TL}$ ) in its mouth (Fig. 1). During the 30-min observation period, neither shark moved position and the wobbegong did not further ingest the bamboo shark. We assume that it would have taken at least several more hours for the wobbegong to completely consume the bamboo shark. Generally, E. dasypogon is known to prey upon invertebrates and small demersal fish, but this unusual field observation highlights its versatility as an ambush predator. With a jaw structure that facilitates dislocation, a large gape, and sharp, rearward-pointing teeth, wobbegongs can grasp relatively large prey before swallowing it whole (Wilga et al. 2007; Prof. J.H. Choat pers. comm.).

Acknowledgments These images were captured during a field trip funded by the National Environment Research Program (NERP). We thank our field assistants Tom Mannering and Andrew Cole, and Professor J. H. Choat for input on shark morphology and feeding.

\section{References}

Compagno LJV (2001) Sharks of the world. An annotated and illustrated catalogue of shark species known to date. Volume 2. Bullhead, mackerel and carpet sharks (Heterodontiformes, Lamniformes and Orectolobiformes). FAO Species Catalogue for Fishery Purposes. No. 1, Vol. 2. Rome, FAO Huveneers C, Otway NM, Gibbs SE, Harcourt RG (2007) Quantitative diet assessment of wobbegong sharks (genus Orectolobus) in New South Wales, Australia. ICES Journal of Marine Science 64:1272-1281

Wilga CD, Motta PJ, Sanford CP (2007) Evolution and ecology of feeding in elasmobranchs. Integrative and Comparative Biology 41:55-69

D. M. Ceccarelli $(\bowtie) \cdot$ D. H. Williamson

Australian Research Council Centre of Excellence for Coral Reef Studies, Townsville, QLD 4811, Australia e-mail: dmcecca@bigpond.net.au

D. M. Ceccarelli

P.O. Box 215, Magnetic Island, QLD 4819, Australia

Received: 9 December 2011 / Accepted: 14 January 2012/Published online: 4 February 2012

Coral Reefs (2012) 31:471

(C) Springer-Verlag 2012 DOI $10.1007 / \mathrm{s} 00338-012-0878-\mathrm{z}$ 